\title{
Характеристика коллекторов фаменских отложений Соликамской впадины
}

\author{
А.В. Плюснин, Т.В. Карасева \\ Пермский государственный национальный исследовательский универси- \\ тет, 614600, Пермь ул. Букарева 15 \\ E-mail: geolog0112@mail.ru \\ (Статья поступила в редакичию 3 апреля 2015 г.)
}

\begin{abstract}
В статье дается характеристика коллекторских свойств пород фаменской карбонатной толщи позднего девона, полученной при изучении керна скважин № 1-4 месторождения им. Сухарева. По результатам детального исследования литологических особенностей продуктивной части авторами были выделены структурные типы и приведено их описание, определены пористость и проницаемость нефтенасыщенных пластов. Изучено строение фаменской части резервуара и дана характеристика основных литотипов. Полученные закономерности распределения продуктивных пород внутри рифа позволят в дальнейшем прогнозировать развитие коллекторов как по разрезу, так и по площади на изучаемой территории.

Ключевые слова: Соликамская впадина, фаменский ярус, риф, коллекторы, пористость, проницаемость.
\end{abstract}

DOI: 10.17072/psu.geol.27.85

В настоящее время почти половина мировой добычи углеводородов осуществляется из карбонатных отложений, которые по прогнозам в будущем будут доминировать в освоении ресурсов. В Пермском крае в карбонатных рифогенных массивах верхнего девона открыто более 118 залежей. Промышленные скопления нефти связаны, главным образом, с зонами развития Камско-Кинельской системы прогибов. Объектом изучения в настоящей работе является залежь нефти в рифогенных отложениях фаменского яруса верхнего девона месторождения им. Сухарева [1,2].

При изучении карбонатной толщи рассматриваемой территории проблема распространения пород-коллекторов должна решаться в совокупности с литологическими исследованиями, так как распространение, свойства и типы пород обусловлены фациальной изменчивостью отложений и вторичными процессами изменения пород [3, 4].

Месторождение им. Сухарева - это новое, крупное месторождение на севере Пермского края. Оно было выявлено сейсморазведкой в 1986 г., а в 2009 г. подготовлено к поисковому бурению с объектами в верхнем девоне, нижнем и среднем карбоне. Месторождение расположено на территории подчинения г. Березники Пермского края, в 155 км на север от краевого центра г. Перми. Ближайшими месторождениями 


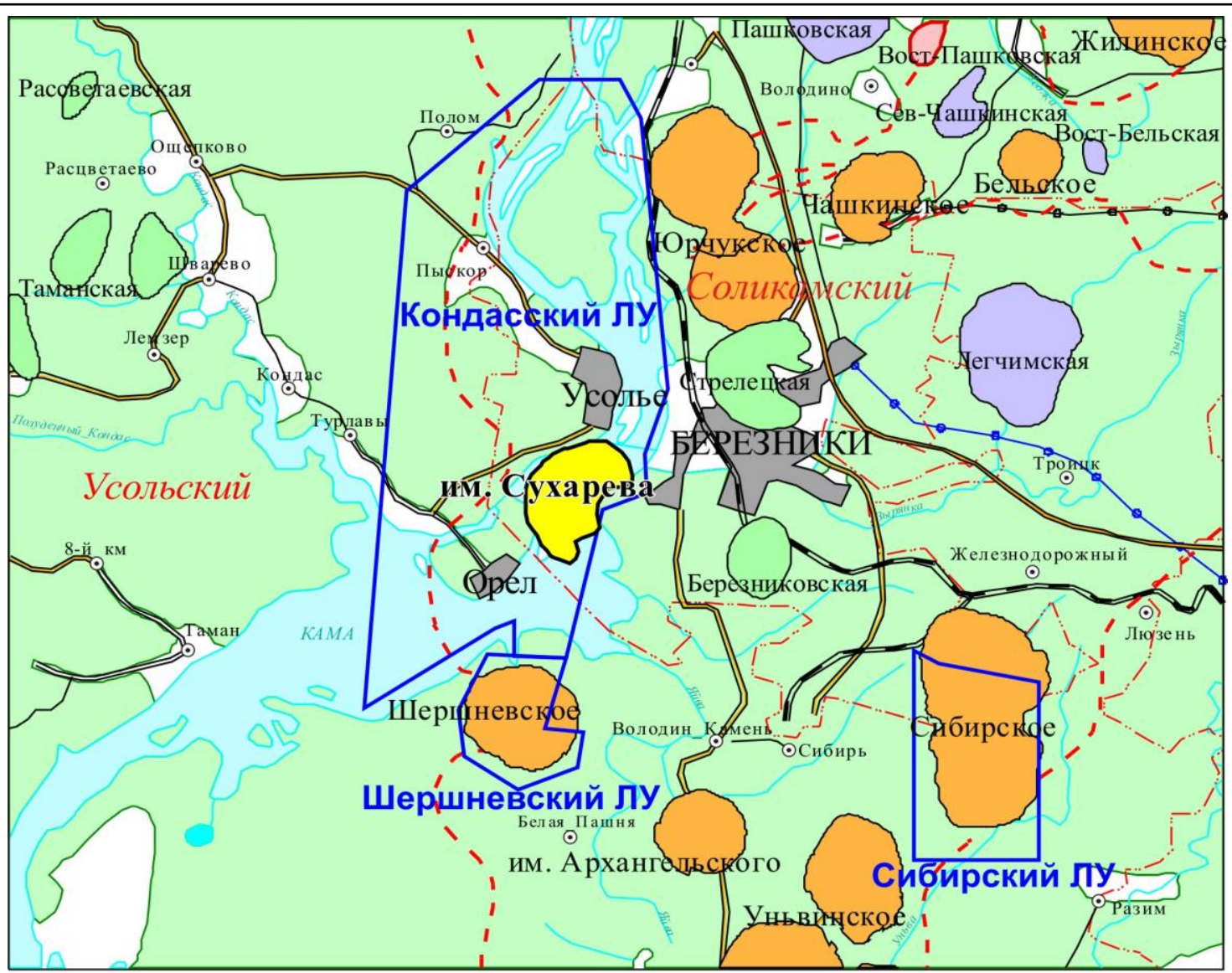

Масштаб 1:300000

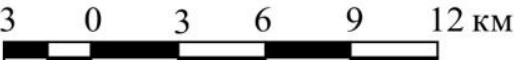

Условные обозначения:

месторождения распределенного фонда

месторождение им.Сухарева

выявленные перспективные структуры

подготовленные к глубокому бурению

структуры, находящиеся в бурении

населеные пункты

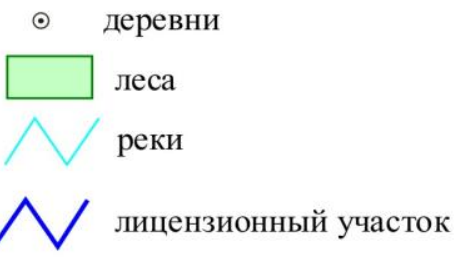

Дороги:

с усоверш. покрытием с покрытием без покрытия грунт. проселочная

Железная дорога:

широкая колея

Трубопроводы:

$\checkmark$ газопровод

' , , граница Верхнекамского месторождения калийных солей 八 границы районов

Рис. 1. Выкопировка из обзорной карты Пермского края (Колчанова, 2009) 
являются Шершневское, им. Архангельского, Уньвинское, Сибирское и Юрчукское (рис.1). В тектоническом отношении месторождение приурочено к крупному куполовидному (Зырянскому) поднятию, расположенному на юго-западе Березниковского палеовыступа центральной части Соликамской впадины во внутренней бортовой зоне Камско-Кинельской системы палеопрогибов [5-7].

В кровле рифа выделяются три гребня, разделенные неглубокими проливами и осложненные семью вершинами различной морфологии. Наиболее морфометрически выраженным является самый западный гребень. В его пределах отмечается максимальная амплитуда, которая по кровле турнейско-фаменских карбонатов составляет 122 м (рис.2) [2].

Тип залежи - пластовая массивная, её размеры 3,8×4,4 км, высота 52,5 м. Нефтенасыщенная толщина пласта изменяется от 8,3 до 17,3 м.

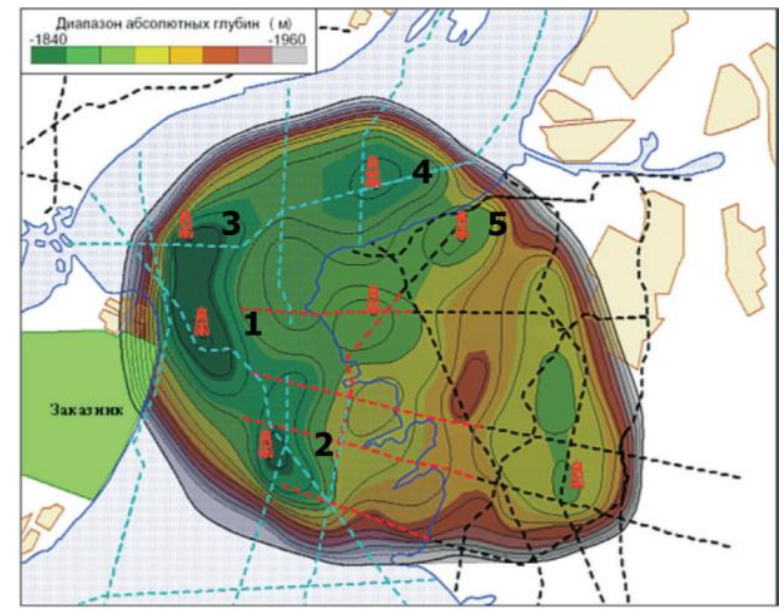

Рис. 2. Структурная карта по кровле турнейско-фаменских отложений мр. им. Сухарева (Неганов, 2013)

В процессе исследования был изучен керн скважин и просмотрены шлифы, что позволило выделить следующие литотипы нефтенасыщеных пластов $[8,9]$.

\section{1. Известняки органогенно-детрито-} вые, образованы сгустками, кальцитовыми сферами и комочками водорослевого происхождения, с остатками водорослей, криноидей и раковинным детритом (рис.
3). Текстура пятнистая с тонкими стилолитовыми швами, промазанными темносерым органическим веществом, с кавернами выщелачивания, инкрустированными разнокристаллическим кальцитом. Поры межформенные, внутриформенные и межзерновые. Размер пор от 0,02 мм до 0,57 мм, отмечаются изолированные и сообщающиеся поры с редкими кавернами (2-5 мм).

Пористость коллекторов изменяется от 7,2 до 15,5 \%, проницаемость, в основном, в пределах $(0,625-73,6) 10^{-3}$ мкм $^{2}$. На гистограмме распределения коэффициентов пористости и проницаемости видно (рис. 4), что наибольшую частоту встречаемости в случае данного типа имеют классы пород-коллекторов с Кп - 14\%, $10 \%$ и 7,13,15 \% (встречаемость 31, 19 и 13\%, соответственно). Преобладающая проницаемость - 0,17-10 и $30-4010^{-3}$ мкм $^{2}$ (встречаемость 32 и 25\%, соответственно). Средние значения коллекторских свойств равны $12,5 \%$ и $24,7210^{-3}$ мкм $^{2}$ по 16 определениям.

Нефтенасыщенные толщины изменяются от 0,5 до 3,8 м, в среднем - 1,7м. Общая нефтенасыщенная толщина пласта в скв. № $1-0,3$ м, скв. № $2-0,5$ м, скв. № $4-3,8$ м.

\section{2.Известняки водорослевые состоят} из сфер, трубочек, сгустков, комочков, сфер микрозернистого кальцита водорослевого происхождения, а также протяжённых вертикально ориентированных водорослевых построек, окруженных сферами, сегментными трубочками и сгустками (рис 3). Текстура узорчатая и пятнистая, обусловлена присутствием водорослевых построек неправильной формы, сложенных колониями сине-зелёных водорослей со сгустковой микроструктурой. Размер пор 0,01 - 0,8 - 1,0 мм, каверны до 4,0 - 11,0 мм (макро- до 20,0 - 40,0 мм). Породы неравномерно трещиноватые, трещины по наслоению и разноориентированные, прослоями многочисленные, пересекающиеся. 
Пористость коллекторов изменяется от 3,1 до $16,7 \%$, проницаемость в основном в пределах $0,12-76,210^{-3}$ мкм $^{2}$. На гистограмме распределения коэффициентов пористости и проницаемости видно (рис.4), что наибольшую частоту встречаемости в данном типе имеют классы пород-коллекторов с Кп 5, 6, 4 и 3\% (встречаемость $26,17,16$ и 14\%, соответственно). Преобладающая проницаемость 0,12-1 и 1-2 $10^{-3}$ мкм $^{2}$ (встречаемость 48 и $11 \%$, соответственно). Средние значения коллекторских свойств равны 6,5 \% по 115 определениям и $1010^{-3}$ мкм $^{2}$ по 109 определениям.

Нефтенасыщенные толщины изменяются от 0,2 до 4,5 м, в среднем составляют 0,9 м. Общая нефтенасыщенная толщина пласта в скв. № $1-16,1$ м, скв. № $3-7,1$ М, в скв. № $4-6,4$ м.

3.Известняки комковатье. Основными форменными компонентами (на 50$60 \%$ ) являются остатки водорослевого происхождения (сферы, сгустки, комочки, трубочки, водоросли), редкие прослои онколитов (рис 3). Прослоями фрагменты водорослевых построек занимают до 40$50 \%$ породы и имеют удлиненную форму. В меньшей степени встречается скудный раковинный детрит и сферы (до 10-20\%). В породе рассеяны остатки зелёных водорослей и редкий раковинный детрит. Текстура пород неоднородная: пятнистая, тонкослоистая и узорчатая, со строматолитоподобной формой построек. Каверны - от редких до многочисленных, размером от 2-5 мм до 25-40 мм. Трещины разноориентированные: сомкнутые (сетка трещин), открытые - нефтяные, многочисленные субвертикальные трещины длинные шириной до 3 мм выполнены кальциTом.

Пористость коллекторов изменяется от 3,4 до $17,7 \%$, проницаемость - в основном в пределах 0,17-1338 $10^{-3}$ мкм $^{2}$. На гистограмме распределения коэффициентов пористости и проницаемости видно (рис.4), что наибольшую частоту встречаемости имеют классы пород-коллекторов с Кп - 3, 4 и 7 \% (встречаемость 47, 24 и $12 \%$, соответственно). Преобладающая проницаемость - 0,17 до 80 мкм $^{2}$ (встречаемость $82 \%$, соответственно). Средние значения коллекторских свойств равны $5,6 \%$ и $108 * 10^{-3}$ мкм $^{2}$ по 17 определениям.

Нефтенасыщенные толщины изменяются от 0,5 до $1,4 \%$, в среднем составляют 0,9 м. Общая нефтенасыщенная толщина пласта в скв. № $2-5,6$ м.

Таким образом, наиболее распространёнными (по мощности) являются водорослевые известняки, затем - органогенно-детритовые и комковатые. По коллекторским свойствам наиболее благоприятными являются органогенно-детритовые, затем - водорослевые и комковатые известняки.

При перфорации в скв. № 1 в интервале 2179,5-2216 м (органогенно-детритовые, водорослевые известняки) получены безводная нефть с дебитом 15,4 т/сут и приток газа дебитом 1,3 тыс. ${ }^{3} /$ сут на 5 ти миллиметровом штуцере.

В скв. № 2 в результате опробования в интервале 2846-2872 м (органогеннодетритовые, комковатые известняки) получена нефть дебитом 58,2 т/сут на 6-ти миллиметровом штуцере.

В скв. № 3 при опробовании интервала 2438,5-2470 м (водорослевые известняки) получена безводная нефть дебитом 22,4 т/сут на 6-ти миллиметровом штуцере.

В скважине № 4 в интервале 2635-2661 м (органогенно-детритовые, водорослевые известняки) получена нефть дебитом 87,1 т/сут на штуцере 6 мм.

Различия в коллекторских свойствах связаны с фациальной зональностью рифов позднего девона. Если рассматривать весь разрез изучаемого рифа, то по чередованию различных типов известняков и их соотношению можно сделать вывод, что скважины вскрыли внутреннею часть рифовой постройки, для которой характерны отложения внутреннего шлейфа, формировавшиеся в периоды снижения относительного уровня моря. Отмечается чередование плотных 

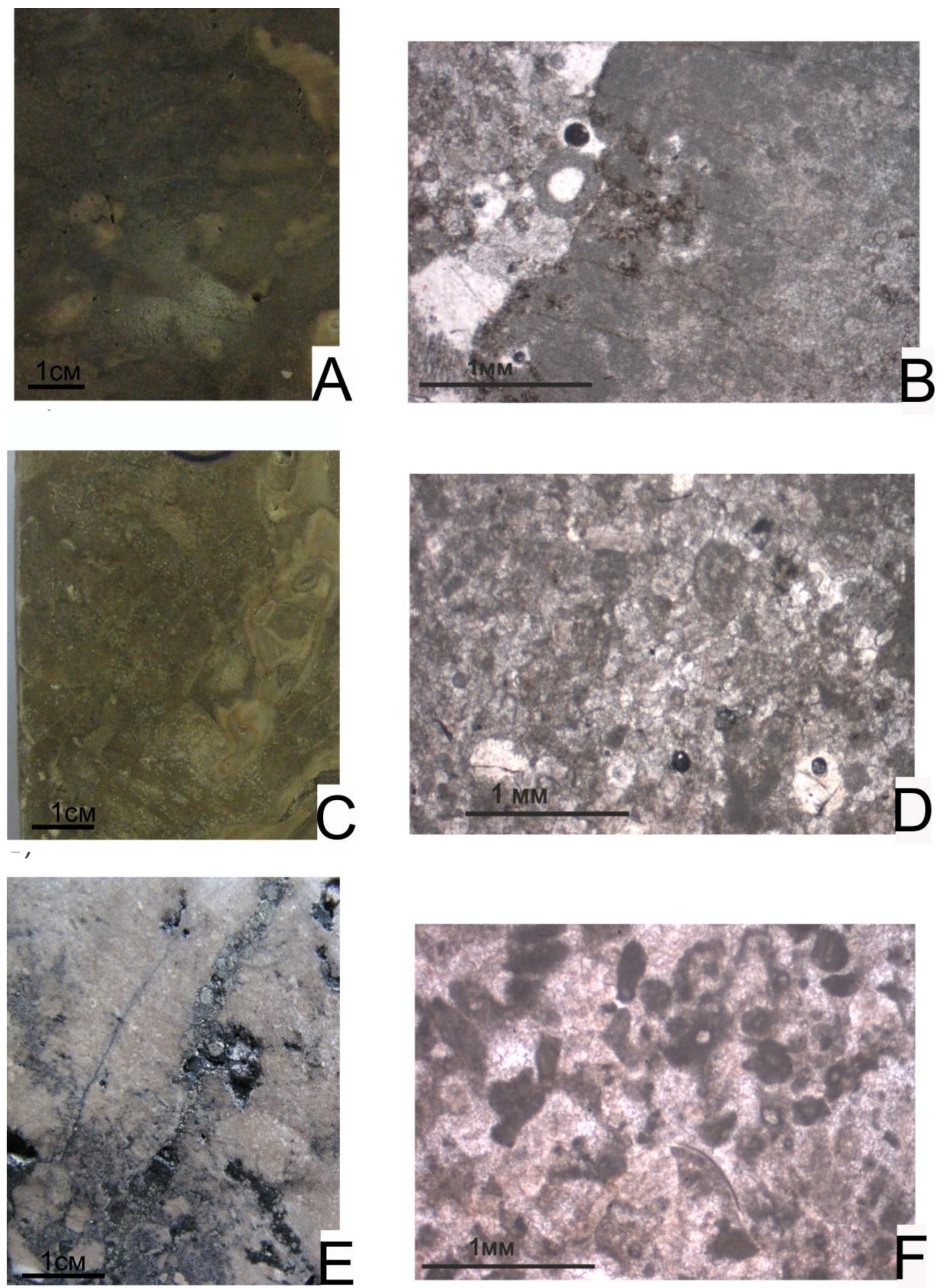

Рис. 3. Фотографии и микрофотографии шилфов: $A$, $B$ - известняк водорослевыгй; $C$, $D$ - известняк комковатый; $E, F$ - известняк органогенно-детритовый 


\section{Водорослевые известняки}
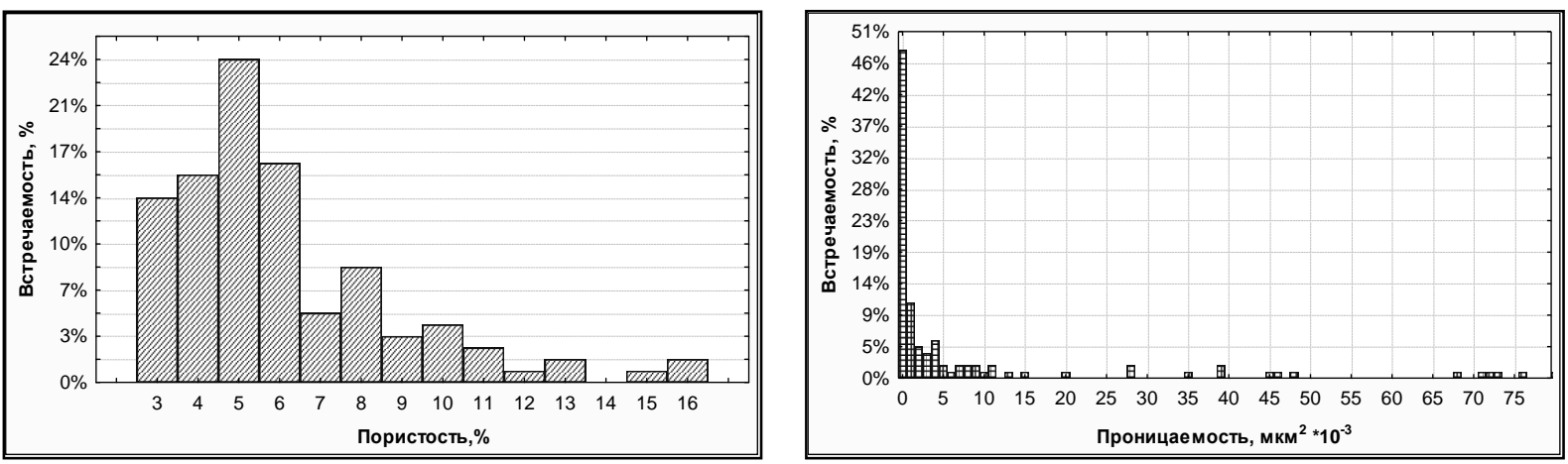

Комковатые известняки
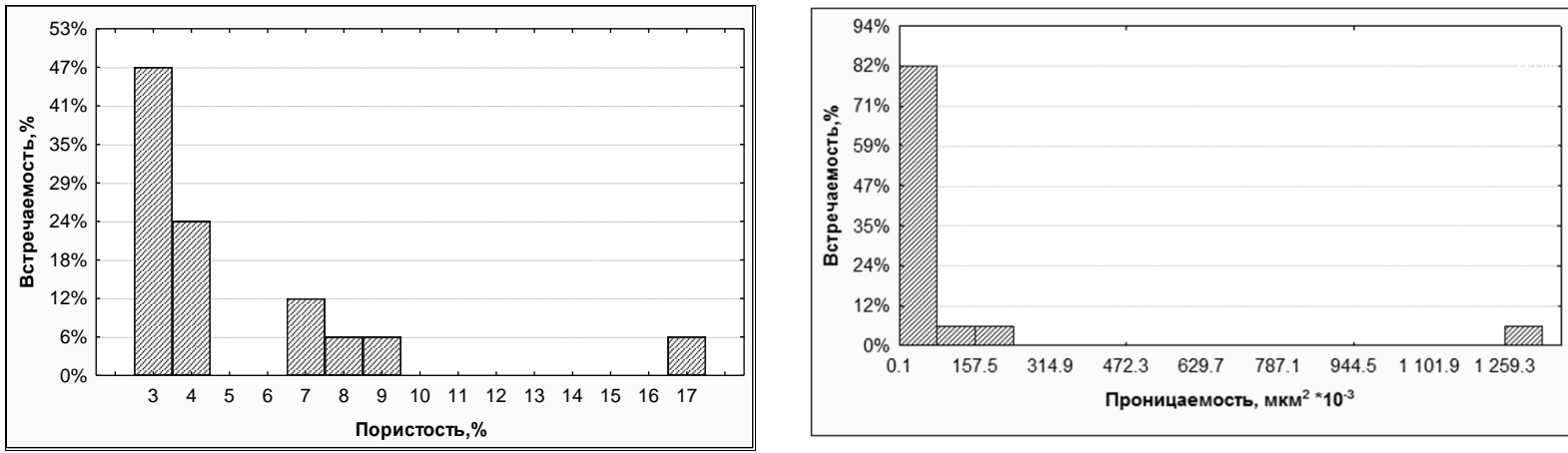

Органогенно-детритовые известняки
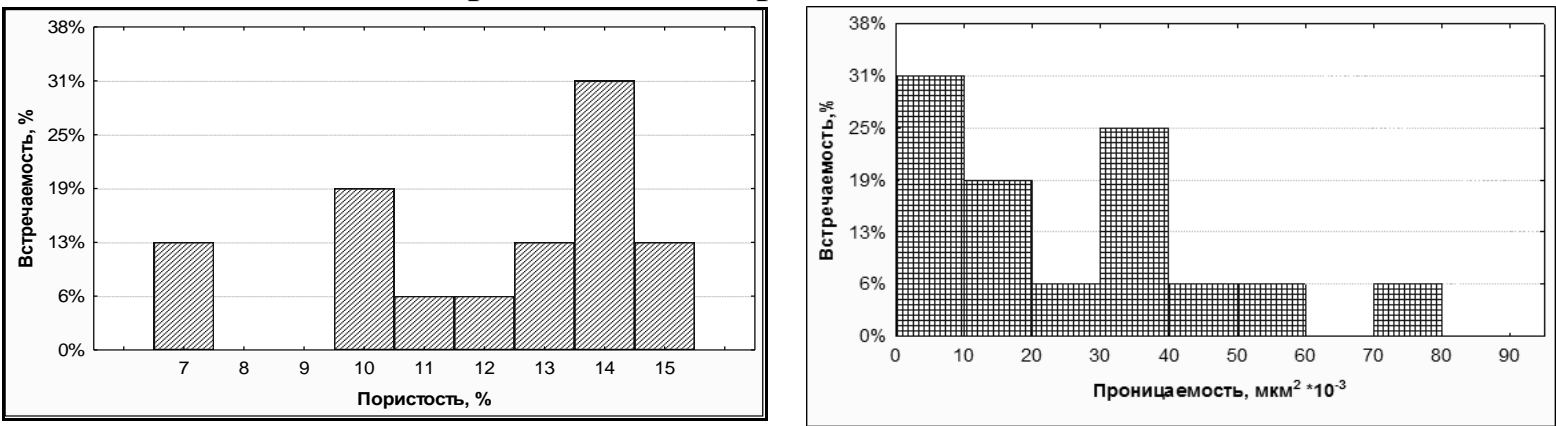

Рис.3. Гистограммы распределения коэффициентов пористости и проницаемости

трансгрессивных водорослевых пачек с проницаемыми водорослевыми известняками регрессивных шлейфовых пачек [10].

Для регрессивных известняков характерна высокая первичная межформенная пористость, которая могла быть увеличена выщелачиванием при максимальном снижении уровня моря; увеличение пустотного пространства произошло также за счет активных процессов трещинообразования. Сходная закономерность распределения коллекторских свойств по разрезу и их литолого-фациальная природа характерны для соседних рифовых массивов: Шершневского, им. Архангельского, Уньвинского, Сибирского и Юрчукского.

Таким образом, получены закономерности распределения различных типов коллекторов продуктивных пород внутри рифового массива, что позволит в дальнейшем прогнозировать коллекторский потенциал как по разрезу, так и по площади в районах распространения рифов на изучаемой территории. 


\section{Библиографический список}

1. Вилесов А.П., Воеводкин В.Л., Сташкова Э.К. Фациальная природа коллекторов верхнедевонских рифогенных массивов северо-восточной части Березниковского палеоплато// Геология, геофизика и разработка нефтяных и газовых месторождений. 2005. №3-4. C. 81-86

2. Колчанова Р.Н., Кузнецова Н.М. Мониторинг Зырянской структуры по материалам сейсморазведки 2D с учетом данных пробуренной скважины 1-Кондасская / ОАО «ПНГ». Пермь, 2012. $11 \mathrm{c.}$

3. Лузина Д.В., Кривощеков С.Н. Анализ фациальных зон и коллекторских свойств турнейско-фаменских рифогенных построек Соликамской депрессии// Вестник Пермского национального исследовательского политехнического университета. Геология. Нефтегазовое и горное дело. 2012. № 5. C. 7-15

4. Лядова Н.А., Яковлев Ю.А., Распопов А.В. Геология и разработка нефтяных месторождений Пермского края / ОАО ВНИИОЭНГ. М., 2010. 335 с.

5. Неганов В.М., Шумилов А.В., Черепанов С.С., Шумский И.Ф. Крупное открытие геофизиков и нефтяников Пермского края начала XXI века // Геофизика. 2013. №5. С. 26-31.
6. Некрасов А.С., Матвеева В.П. Пространственная корреляция фаменско-турнейских карбонатных отложений сибирского месторождения и их литолого-фациальное районирование // Геология, геофизика и разработка нефтяных и газовых месторождений. 2005. № 5-6. С. 43-48.

7. Некрасов А.С. Геолого-геофизические исследования карбонатных коллекторов нефтяных месторождений / Перм. ун-т. Пермь, 2006. 422 с.

8. Плюснин А.В. Литотипы разреза Зырянского рифа в связи с нефтегазоносностью // Геология и полезные ископаемые Западного Урала / Перм. гос. нац. иссл. ун-т. Пермь, 2014. С. 74-76.

9. Плюснин А.B. Характеристика турнейскофаменских отложений Зырянского рифа // Вестник молодых ученых Пермского государственного национального исследовательского университета [Электронный ресурс]: сб. науч. тр. / отв. редактор В.А. Бячкова; Перм. гос. нац.исслед. ун-т. Электрон. дан. Пермь, 2014. Вып. 4. С. 399-408

10.Сташкова Э.К., Беляева Н.В. Геологическое моделирование, коллекторы и последовательность разработки на примере одного из месторождений Пермского края // Геология, геофизика и разработка нефтяных и газовых месторождений. 2007. №7. C. 51-56.

\title{
Reservoir Characteristic of Famennian Deposits of the Solikamsk Depression
}

\author{
A.V. Plyusnin, T.V. Karaseva \\ Perm State University, 15 Bukireva Str., Perm 614600, Russia. \\ E-mail: geolog0112@mail.ru
}

The article describes the reservoir rock properties of Famennian (Late Devonian) reef carbonate strata obtained by core study at boreholes № 1-4 of the Sukharev oil field. Based on the results of detailed study of lithological features of productive strata, authors defined the structural types and composed their description. The characteristics of the porosity and permeability of oil-bearing beds were shown. In a result of studies, the structure and main lithotypes of Famennian portion of reservoir were determined that allowed predicting the spatial distribution of reservoir properties within oilfield area.

Keywords: Solikamskaya depression; Famennian reef; reservoir; porosity; permeability. 


\section{References}

1. Vilesov A.P., Voevodkin V.L., Stashkova E.K. 2005. Fatsialnaya priroda kollektorov verkhnedevonskikh rifogennykh massivov severovostochnoy chasti Bereznikovskogo paleoplato [Facial nature of reservoirs of the Upper Devonian reef massifs of north-east part of the Bereznikovskoe paleoplato]. Geologiya, geofizika i razrabotka neftyanykh i gazovykh mestorozhdeniy, 3-4: 81-86. (in Russian)

2. Kolchanova R.N., Kuznetsova N.M. 2012. Monitoring Zyryanskoy struktury po materialam seysmorazvedki 2D s uchetom dannykh proburennoy skvazhiny 1-Kondasskaya [Monitoring of Zyryanskaya oilfield based on data of 2D seismics and borehole 1 Kondasskaya]. Report JSC «PermNefteGeofizika», Perm, p. 11. (in Russian)

3. Luzina D.V., Krivoshchekov S.N. 2012. Analiz fatsialnykh zon i kollektorskikh svoystv turneysko-famenskikh rifogennykh postroek Solikamskoy depressii [Analysis of facial zones and reservoir properties of the Tournaisian - Famennian reef structures of Solikamskaya depression]. Vestnik PNIPU. Geologiya. Neftegazovoe i gornoe delo. 5: 715. (in Russian)

4. Lyadova N.A., Yakovlev Yu.A., Raspopov A.V. 2010. Geologiya i razrabotka neftyanykh mestorozhdeniy Permskogo kraya [Geology and development of oil fields of the Perm Kray]. Moskva, JSC VNIIOENG, p. 335. (in Russian)

5. Nekrasov A.S., Matveeva V.P. 2005. Prostranstvennaya korrelyatsiya famenskoturneyskikh karbonatnykh otlozheniy Sibirskogo mestorozhdeniya i ikh litologofatsialnoe rayonirovanie [Spatial correlation of Famennian - Tournaisian carbonates of the Siberian deposit and their lithofacial zoning]. Geologiya, geofizika I razrabotka neftyanykh i gazovykh mestorozhdeniy, 5-6: 43-48. (in Russian)

6. Neganov V.M., Shumilov A.V., Cherepanov S.S., Shumskiy I.F. 2013. Krupnoe otkrytie geofizikov i neftyanikov Permskogo kraya nachala XXI veka [Major discovery of geophysicists and oilmen of the Perm Kray in beginning of the XXI century]. Geofizika, 5: 26 - 31. (in Russian)

7. Nekrasov A.S. 2006. Geologo-geofizicheskie issledovaniya karbonatnykh kollektorov neftyanykh mestorozhdeniy [Geological and geophysical studies of carbonate reservoirs of oil fields]. Perm State Univ., Perm, p. 422. (in Russian)

8. Plyusnin A.V. 2014. Litotipy razreza Zyryanskogo rifa $\mathrm{v}$ svyazi s neftegazonosnostyu [Lithotypes of Zyryansky reef relative to the oil and gas content]. In Geologiya $\mathrm{i}$ poleznye iskopaemye Zapadnogo Urala, Materialy Konf. Ed. R.G. Iblaminov, Perm. gos. national issl. Univ., Perm, pp. 74-76. (in Russian)

9. Plyusnin A.V. 2014. Kharakteristika turneysko-famenskikh otlozheniy Zyryanskogo rifa [Characteristics of the Tournaisian Famennian deposits of Zyryansky reef]. Vestnik molodykh uchenykh PGNIU [Elektronnyyresurs]. 4: 399-408. (in Russian)

10.Stashkova E.K., Belyaeva N.V. 2007. Geologicheskoe modelirovanie, kollektory i posledovatelnost razrabotki na primere odnogo iz mestorozhdeniy Permskogo kraya [Geological modeling, resrvoirs and development order on example of an oilfield of Perm Kray]. Geologiya, geofizika i razrabotka neftyanykh i gazovykh mestorozhdeniy. 7: 5156. (in Russian) 